\title{
Prevention of Mutation, Cancer, and Other Age-Associated Diseases by Optimizing Micronutrient Intake
}

\author{
Bruce N. Ames \\ Nutrition and Metabolism Center, Children's Hospital Oakland Research Institute, 5700 Martin Luther King Jr. Way, \\ Oakland, CA 94609, USA \\ Correspondence should be addressed to Bruce N. Ames, bames@chori.org
}

Received 8 June 2010; Accepted 30 July 2010

Academic Editor: Ashis Basu

Copyright ( $\odot 2010$ Bruce N. Ames. This is an open access article distributed under the Creative Commons Attribution License, which permits unrestricted use, distribution, and reproduction in any medium, provided the original work is properly cited.

I review three of our research efforts which suggest that optimizing micronutrient intake will in turn optimize metabolism, resulting in decreased DNA damage and less cancer as well as other degenerative diseases of aging. (1) Research on delay of the mitochondrial decay of aging, including release of mutagenic oxidants, by supplementing rats with lipoic acid and acetyl carnitine. (2) The triage theory, which posits that modest micronutrient deficiencies (common in much of the population) accelerate molecular aging, including DNA damage, mitochondrial decay, and supportive evidence for the theory, including an in-depth analysis of vitamin $\mathrm{K}$ that suggests the importance of achieving optimal micronutrient intake for longevity. (3) The finding that decreased enzyme binding constants (increased $\mathrm{Km}$ ) for coenzymes (or substrates) can result from protein deformation and loss of function due to an age-related decline in membrane fluidity, or to polymorphisms or mutation. The loss of enzyme function can be compensated by a high dietary intake of any of the B vitamins, which increases the level of the vitamin-derived coenzyme. This dietary remediation illustrates the importance of understanding the effects of age and polymorphisms on optimal micronutrient requirements. Optimizing micronutrient intake could have a major effect on the prevention of cancer and other degenerative diseases of aging.

\section{Lipoic Acid and Acetyl-Carnitine Supplements Decrease the Oxidative Mitochondrial Decay of Aging}

Mitochondrial decay appears to be a major contributor to aging and its associated degenerative diseases including cancer and neural decay $[1,2]$. Mitochondria from old rats compared with those from young rats generate increased amounts of mutagenic [3-5] oxidant by-products [6] and have decreased membrane potential, respiratory control ratio, cellular oxygen consumption, and cardiolipin (a key lipid found in mitochondria). Oxidative damage to DNA, RNA, proteins, and mitochondrial membrane lipids contributes to this decay [6-10] and leads to functional decline of mitochondria, cells, tissues, and eventually organs such as the brain, with an accompanying loss of cognition and ambulatory activity [6-10].

Decreased capacity to produce ATP and increased oxidant production are two properties of aging mitochondria supported by multiple lines of direct and indirect observations. First, the analysis of gene expression profiles in mice showed significant age-associated declines in the mRNA levels of mitochondrially encoded subunits of complex I, III, IV, and V in old compared to young mice [11]. Second, in addition to reduced gene expression, the levels of mutagenic $[3,4]$ aldehydes [12] and oxidants increase in aging tissues.

The importance of optimizing metabolic function to prevent mitochondrial decay is illustrated by feeding the mitochondrial metabolites acetyl carnitine (ALC) [13-15] and R-alpha lipoic acid (LA) [16] to old rats. Carnitine is used for transporting fatty acids into the mitochondria; the main short-chain acyl-carnitine is ALC [17]. In humans at rest, ALC accounts for roughly a quarter of total carnitine in plasma, muscle, and liver tissues [17]. LA is a mitochondrial coenzyme and is preferentially reduced in the mitochondria to a potent antioxidant. LA is also an effective inducer of the transcription factor $\mathrm{Nrf2}$, which in turn induces the glutathione synthesis enzymes [18-20]. Nrf2 induces over 
200 phase- 2 antioxidant and thiol-protective enzymes [21, 22]. ALC and LA, when added as a supplement, can act in some cases synergistically, to restore much of the lost mitochondrial function in old rats [6-9].

One possible mechanism of mitochondrial decay is that with age, stiffer membranes due to lipid oxidation or increased oxidative damage to mitochondrial proteins cause structural deformation of key enzymes such as carnitine acyl transferase that lowers their affinity for the enzyme substrate [9]. Feeding old rats the substrate ALC with LA for a few weeks decreases oxidative damage, allowing the synthesis of new carnitine acyl transferase with normal binding affinity (Km) [9]. This partially restores mitochondrial function, decreases mutagenic oxidants, neuronal RNA oxidation, and mutagenic aldehydes, and increases rat ambulatory activity and cognition [6-9]. ALC and LA are not usually thought of as micronutrients, as they can be synthesized in the body, but they are illustrative of many normal metabolites that decline with age and may be beneficial as supplements in the elderly.

Park et al. [23] used DNA microarrays to identify transcriptional markers of aging that are differentially expressed in young versus old mice of multiple inbred strains. They then fed the mice various metabolites, mostly antioxidants, to see if they would oppose these transcriptional markers of aging, comparing effectiveness to caloric restriction, a known potent method for delaying aging. ALC was as effective as caloric restriction in the heart and LA was as effective in the cerebellum. These experiments suggest that ALC + LA is an effective caloric restriction mimetic and that tuning up metabolism may help in slowing down the aging process. The tissue specific effects of caloric restriction-mimetic agents suggest that a combinatory approach may be needed.

\section{Triage Theory Suggests a Cause of Much Preventable Mutation and Cancer}

The "triage theory" [24-26] provides a unifying rationale for a causal link between chronic modest deficiency of a micronutrient $(\sim 40$ essential minerals, vitamins, amino acids, and fatty acids) and the many degenerative diseases accompanying aging such as cancer, immune dysfunction, cognitive decline, cardiovascular disease, and stroke. If the theory is correct, the incidence of these diseases might be reduced by an inexpensive micronutrient intervention [24-26].

Triage theory $[24,25]$ posits that during evolution, as a result of periods of shortage of micronutrients required by various proteins for function, nature was selected for a rebalancing of metabolism (e.g., by selection for strong micronutrient binding constants for critical proteins). This rebalancing ensured survival of the organism at the expense of metabolism whose lack caused the accumulation of insidious damage leading to longer-term consequences, that I proposed including chronic diseases of aging. That nature may have developed such a system is logically consistent with the consensus that natural selection favors shortterm survival for reproduction over long-term health [27]. During evolution micronutrient shortages were likely to be very common, For example, the 15 essential minerals are not distributed evenly on the earth; dietary sources and availability also fluctuated markedly [28].

The triage theory predicts that optimizing intake of the $\sim 40$ essential micronutrients will reduce the risk of chronic diseases associated with aging and increase lifespan [24]. Micronutrients are remarkably inexpensive. Micronutrient intakes below recommended levels are unusually widespread in poor countries, but also in the US population in all segments of society, especially the poor, children, adolescents, the obese, and the elderly. High consumption of calorierich, micronutrient-poor unbalanced diets exacerbates the problem [24]. For example, over half of the US population have inadequate intakes of magnesium [24], almost all African-Americans are extremely low in vitamin D [29], and much of the population is low in a variety of other micronutrients, (e.g., omega-3 fatty acids, potassium, calcium, vitamin $\mathrm{C}$, vitamin $\mathrm{E}$, vitamin $\mathrm{K})[24,30,31]$. There is little societal concern because no overt pathologies have been associated with marginal to moderate levels of deficiency. The triage theory predicts that the pathology is insidious, but we believe that it is measurable. We hypothesize that two of the many insidious, but measurable, consequences of moderate micronutrient inadequacy are increased DNA damage (future cancer) and mitochondrial decay (mutagenic oxidant release, future cancer, and cognitive dysfunction) as aspects of a triage response. These consequences are known to increase with age. In addition, evidence from our own work and that of others, as briefly reviewed below, indicates that sensitive assays targeted at these endpoints have a high likelihood of detecting changes in individuals with moderate micronutrient deficiencies. Other age-related diseases, such as cardiovascular disease and immune dysfunction [25] are also increased by micronutrient deficiencies and are discussed elsewhere $[25,30]$.

2.1. Vitamin $K$ as an Example of the Utility of Triage Theory [30]. For 16 known vitamin K-dependent (VKD) proteins, we evaluated the relative lethality of 11 known mouse knockout mutants to categorize essentiality. Results indicated that 5 VKD proteins required for coagulation had critical functions (knockouts were embryonic lethal), whereas the knockouts of 5 less critical VKD proteins [osteocalcin, matrix Gla protein (Mgp), growth arrest specific protein 6 (Gas6), transforming growth factor $\beta$-inducible protein (Tgfbi or $\beta$ ig-h3), and periostin] survived at least through weaning. The VKD $\gamma$-carboxylation of the 5 essential VKD proteins in the liver and the 5 nonessential proteins in nonhepatic tissues sets up a dichotomy that takes advantage of the preferential distribution of dietary vitamin $\mathrm{K} 1$ to the liver to preserve coagulation function when vitamin $\mathrm{K} 1$ is limiting. Genetic loss of less critical VKD proteins, dietary vitamin $\mathrm{K}$ inadequacy, human polymorphisms or mutations, and vitamin $\mathrm{K}$ deficiency induced by chronic anticoagulant (warfarin/coumadin) therapy are all linked to age-associated conditions [30]: bone fragility after estrogen loss (osteocalcin); increased risk of type 2 diabetes (Gas6) [32]; arterial calcification (Mgp) [33, 34]; calcific aortic valve disease (periostin) [35]; increased chromosomal aberrations and spontaneous 
cancer with mitotic spindle abnormalities (Tgfbi) [30, 36]. Studies on vitamin $\mathrm{K}$ deficiency as a cause of cancer are few but are suggestive $[36,37]$. A triage perspective reinforces recommendations of some experts that much of the population and warfarin/coumadin patients may not receive sufficient vitamin $\mathrm{K}$ for optimal function of VKD proteins that are important to maintain long-term health [30].

2.2. DNA Damage and Cancer. Deficiency in each of the 7 micronutrients (iron, magnesium, zinc, and vitamins B6, C, folic acid, and biotin) that we have so far examined results in increased DNA damage in rodents, primary human cells in culture, or humans [24,38-42]. Deficiency was severe in many of these studies, but further evidence discussed below suggests that modest levels of deficiency also can result in DNA damage and cancer.

Folate deficiency at moderate levels was the first micronutrient inadequacy to be clearly established as a mutagenic hazard for a considerable percentage of the US population. Low folate in mice was shown to cause chromosome breaks [43] and cancer [44]. Folate deficiency in human cells in culture was accompanied by chromosome breaks, cell cycle arrest in the S-phase, apoptosis, and high uracil incorporation into DNA, a likely cause of the breaks [38, 45-47]. A comparison of folate deficiency with radiation in breaking chromosomes has been done by us [38] and others [48, 49]. Folate deficiency in ex vivo human lymphocytes causes aneuploidy [50] and increased DNA oxidation and decreased DNA repair in rats [51]. Moderate deficiency of folate in humans (before folate supplementation of flour in the US) caused chromosome breaks at levels of deficiency present in $10 \%$ of the US population and in half of low income adolescents and elderly [47, 52, 53]. A study of human folate deficiency and micronuclei (chromosome breaks) [52] should have been the seminal paper in the nutrition-cancer field but has not been sufficiently appreciated. Micronuclei as a measure of chromosome breaks have been validated as a predictor of future human cancer [54]. In studies of Australian healthy adults, the third of the population with the lowest folate levels had a significantly increased level of chromosome breaks $[55,56]$. Moderate folate deficiency has also been associated with human cancer, as reviewed in $[51,57,58]$. Moderate deficiency in B12 causes chromosome breaks in humans, apparently by the same mechanism as folate deficiency $[53,55]$.

Magnesium Deficiency. Magnesium intakes for $\sim 56 \%$ of adults in the United States are below the Estimated Average Requirement (EAR), the current measure of micronutrient inadequacy (the RDA is set at 2 standard deviations above the EAR). Intakes below the EAR are especially prevalent among the poor, teenagers ( $78 \%$ of 14 - to 18 -year-old males and $91 \%$ of 14 - to 18 -year-old females), the obese, African Americans, and the elderly (81\%) [31, 59-63]. Moderate magnesium deficiency causes genetic instability [64]. In humans, moderate magnesium deficiency has been associated with colorectal and other cancers [64-69], hypertension, stroke, osteoporosis, diabetes, and the metabolic syndrome [67, 70-72]. In a study of 4,035 men followed for 18 years, the highest quartile with serum magnesium at baseline compared with the lowest had a $40 \%$ decrease in all-cause mortality and cardiovascular disease and a 50\% decrease in cancer deaths [69]. In primary human cells in culture, magnesium deficiency leads to accelerated telomere shortening, activation of cell-cycle arrest proteins, premature senescence [41], and mitochondrial DNA damage (D. W. Killilea, B. N. A., unpublished observations). Magnesium deficiency in rats leads to chromosome breaks [73] and cancer [64]. In rats, a diet moderately deficient in magnesium increased mortality, blood pressure, inflammation, and oxidants and decreased resistance to oxidants compared with a standard or magnesium-supplemented diet [74]. This evidence suggests that supplementation programs should be considered because there is little risk of magnesium toxicity [70]. Good sources of magnesium are greens (magnesium is in the center of the chlorophyll molecule), whole grains, and nuts. A standard multivitamin-mineral (MVM) supplement does not contain sufficient magnesium (or calcium) because it would make the supplement too bulky.

Vitamin $B 6$ deficiency, as measured by pyridoxal phosphate (PLP) levels in plasma, is associated with colorectal cancer; colorectal cancer decreased by $49 \%$ for every 100 $\mathrm{pmol} / \mathrm{mL}$ increase in blood PLP level [75]. Serum levels of PLP were inversely associated with lung cancer in both smokers and nonsmokers in the EPIC study $(100,000$ person years) [76]. A significant inverse association between PLP level and gastric cancer has been shown in a large cohort study [77]. One possible mechanism is deficiency of B6 causing interference with heme biosynthesis causing release of mutagenic oxidants [24] though other mechanisms are also possible [78]. A sizeable percentage of the population not using supplements has inadequate PLP levels [79]; 49\% of elderly women have inadequate (<EAR) B6 intake [31]. Low PLP levels are also associated with depression [80] and stroke [81].

Moderate deficiencies of calcium, niacin, vitamin E, retinol [56], or vitamins A, C, or E [82] are associated with chromosome damage. Severe deficiencies in rodents or human cell cultures for selenium, copper, niacin, choline, pantothenate, or riboflavin are also associated with chromosome breaks $[24,56]$. Many of these and other moderate micronutrient deficiencies, when studied epidemiologically, are associated with cancer [24, 69, 83-93]. A number of human intervention studies with micronutrients report a decrease in DNA damage or cancer [52, 94-96] though more studies are needed to reach a definitive conclusion. The limitations of experimental approaches available for demonstrating a causal relation between micronutrient deficiency and cancer have been pointed out [97, 98]; a critical analysis of this large literature is not attempted here.

2.3. Mitochondrial Oxidant Release. A large literature, as discussed in Section 1, provides evidence that mitochondrial decay occurs with age and results in increased production of mutagenic oxidant byproducts of electron transport. To the extent that the DNA damage is caused by oxidants released from mitochondria, mtDNA will be damaged before nuclear DNA and should be more easily detected. Mitochondrial 
decay appears to be a major contributor to both aging and its associated degenerative diseases, such as cancer and brain dysfunction, for example, complex I and Parkinson's disease, complex IV and Alzheimer's disease [24]. In mice, or human cells in culture, we found that severe deficiencies in zinc [42], iron [40], biotin [39], or vitamin B6 resulted in increased mitochondrial oxidative decay [24]. In all 4 cases, the mechanism could involve inhibition of heme synthesis which lowers levels of complex IV $[24,39]$, as discussed below.

\subsection{Some Micronutrient Deficiencies Impair Heme Synthesis,} Which Can Result in Oxidative Stress, Mitochondrial Decay, DNA Damage, and Cell Senescence. Seven micronutrients (biotin, pantothenate, pyridoxine, riboflavin, copper, iron, and zinc) are required for heme synthesis in mitochondria. A severe deficiency in any of these seven will cause a deficit of heme and therefore of complex IV, of which heme-a is an essential component $[39,99-103]$. This mechanism is compatible with a triage response if complex IV is sensitive to modest deficiencies as well. The normal complement of complex IV keeps oxidants to a minimum; deficits of complex IV result in oxidant leakage, DNA damage, accelerated mitochondrial decay, and cellular aging [39, 99103]. Deficiencies of iron, zinc, and biotin are discussed below.

Iron. Iron deficiency is the most common micronutrient deficiency in the world, and anemia is widespread in underdeveloped countries [104]. Iron intake in US menstruating women is low; $\sim 16 \%$ are below the EAR, the standard measure of inadequacy [31]. Hispanic women and the obese are at greater risk of being iron deficient [105]. In humans, iron deficiency anemia is associated with poor cognitive development in toddlers [106-110], suggesting that iron deficiency in humans during critical periods of development harms the developing brain $[107,108,111]$. Severe iron deficiency causes loss of mitochondrial complex IV in selected regions in the brain of neonatal rats [112] as well as other changes in function, morphology, and physiology of the brain [107, 113]. Iron deficiency or excess in rats damages mitochondria and causes oxidant release, oxidative DNA damage, and decreased mitochondrial efficiency at levels both below and above the optimum [40].

Functional iron deficiency also is associated with diminished immune function and neuromuscular abnormalities $[114,115]$. The effects of iron deficiency occur along a continuum [40, 107, 116]. Mitochondrial oxidant release resulting from nonsevere iron deficiency [40] could possibly be due to effects on heme-a biosynthesis [102, 103]. Iron deficiency without anemia can also occur in newborns exposed to intrauterine hypoxia, such as infants of preeclamptic or diabetic mothers [117]. In such cases, iron is prioritized to erythroid and hemoglobin synthesis, putting the nonerythroid tissues at risk of iron deficiency and hence heme deficiency $[118,119]$. Dietary iron deficiency in the absence of anemia decreases aerobic capacity and physical work performance, which are improved by iron supplementation [120]. Iron deficiency has not been adequately studied as a possible risk factor for cancer and the results are discordant [121, 122]. Many studies are looking for a monotonic relationship and do not take into account that one might expect cancer at levels of iron that are both too low and too high [40], as in hereditary hemochromatosis, a known risk factor for cancer [123]. Both iron deficiency and excess iron (excess iron may cause zinc or copper deficiency) in mice cause oxidant leakage from mitochondria, oxidative mtDNA damage, and mitochondrial dysfunction [40]. Iron accumulates with age and causes mitochondrial damage and early senescence in human cells in culture [124] and in rats [125]. Excess iron in human cells causes mitochondrial dysfunction, which can be ameliorated by ALC and LA [126].

Zinc. Zinc inadequacy is common in adults, $\sim 12 \%$ of whom are below the EAR [31]. In human cells in culture, severe zinc deficiency causes complex IV deficiency and the release of oxidants, resulting in significant oxidative damage to DNA $[42,127,128]$. Zinc deficiency also causes chromosome breaks in rats [73] and is associated with cancer in both rodents and humans [129]. As discussed above, these observations reinforce the need to determine what degree of deficiency in humans results in DNA damage. We think it is likely that the trigger for decreased heme synthesis is the inactivation of the second enzyme of the pathway, $\delta$-aminolevulinate dehydratase, which contains 8 atoms of zinc $[102,130]$. Zinc deficiency in human cells also inactivates other zinc-containing proteins such as the tumor suppressor protein p53 and the DNA base excision repair enzyme, apyrimidinic/apurinic endonuclease, with a resulting synergistic effect on genetic damage $[42,127]$.

Biotin. Biotin deficiency is more common than previously thought; $\sim 40 \%$ of pregnant women who do not take a multivitamin show metabolic signs of deficiency [131]. Marginal biotin deficiency is teratogenic in mice [131]. Biotin is a prosthetic group in 4 biotin-dependent carboxylases (3 of which are solely present in mitochondria) that replenish intermediates in the tricarboxylic acid cycle [132]. Biotin deficiency decreases the activity of these enzymes, leading to a decrease of 2 heme precursors, mitochondrial succinylCoA, and glycine, thus resulting in heme deficiency [39]. Biotin deficiency in normal human lung fibroblasts in culture caused a 40-50\% decrease in heme content, oxidant release, premature senescence, and DNA damage [39]. The relationship of these effects to human intake amounts needs to be determined [133].

Despite the promise of decreasing mutation rates by optimizing metabolism, a cautionary note is that too much of some micronutrients, such as iron [40] or selenium $[134,135]$, as well as too little, can be harmful. Several micronutrients, for example, folate $[58,136,137]$ or vitamin $\mathrm{K}[30,138]$, may stimulate previously existing cancer cells. It should not be assumed that "too much of a good thing is wonderful." Mae West, who said that, was not thinking about micronutrients. 


\section{Ameliorating Some Consequences of Mutation: Enzymes Lose Binding Affinity (Increased Km) for Coenzymes and Substrate with Mutation or Age}

We reviewed [139] about 50 human genetic diseases due to defective enzymes, which were remedied or ameliorated by the administration of high doses of the vitamin component of the corresponding coenzyme, thus partially restoring enzyme activity. Up to a quarter of mutations in a gene result in the corresponding enzyme having a decreased binding constant (increased $\mathrm{Km}$ ) for a coenzyme resulting in a lower rate of reaction [139]. The review points out that many of the $\mathrm{B}$ vitamins, given at levels 10-100 times the RDA, can raise coenzyme activity levels by an order of magnitude or more, usually with minimal toxicity. Several single-nucleotide polymorphisms (SNPs) with a deleterious phenotype, under some conditions, decrease binding constants and thus may also be remediable by raising cellular concentrations of the cofactor by high-dose vitamin therapy. Our review raised the issue of whether some appreciable percentage of the population may require a higher level of a particular vitamin or substrate for optimum function.

A follow-up review [140] points out that it is common for proteins to become deformed with age, for example, membranes become stiffer by oxidation, deforming membrane proteins, and particularly in mitochondria. This raises the question of whether high dose B vitamins may be beneficial in the elderly. Deformation of an enzyme commonly decreases binding affinity (increased $\mathrm{Km}$ ) for its coenzyme or substrate. Enzyme substrates and vitamin precursors of coenzymes can be elevated by feeding and may enhance the activity of a deformed enzyme. These observations also reinforce the importance of including age in dietary recommendations. For example, for vitamin B12, there is a special recommendation for the elderly based on their increased requirement, due to loss of uptake [141]. It also raises the question whether many metabolites, as well as vitamins, might be fed to improve functioning of enzymes in the elderly. The remediation of deformed enzymes, whether due to mutation or aging, is a field that shows promise and may be an inexpensive way to improve health.

The substrate binding affinities of complex I, III, and IV in mitochondria isolated from muscle of young and old mice were examined [142]. A kinetic analysis of complex III revealed a significant $29 \%$ age-associated increase in the $\mathrm{Km}$ (decreased binding) for ubiquinone-2. More recent work [143] reported a defect in the ubiquinone-binding site of cytochrome $b$ in complex III in the interfibrillary mitochondria isolated from old rats [143]. The resulting defect in ubiquinone binding affinity is likely to increase superoxide production at this site. One possible mechanism of mitochondrial decay is that with age, stiffer membranes due to lipid oxidation or increased oxidative damage to mitochondrial proteins causes structural deformation of key enzymes such as carnitine acyl transferase that lowers their affinity for the enzyme substrate. Feeding old rats the substrate ALC with LA for a few weeks decreases oxidative damage, allowing the synthesis of new carnitine acyl transferase with normal binding affinity $(\mathrm{Km})$ [9]. This partially restores mitochondrial function, decreases oxidants, neuronal RNA oxidation, and mutagenic aldehydes, and increases rat ambulatory activity and cognition [6-9]. Mitochondrial complexes were examined [144] in the brain of young and old rats, with and without dietary ALC and LA. ALC and LA partially restored function of complex I to the level of the young, but by restoring Vmax, not Km for CoQ and NADH [144]. Increased levels of CoQ and niacin might overcome the increased $\mathrm{Km}$. The $\mathrm{Km}$ mechanism for restoring function is not the only possible one; decreased oxidants may increase protein activity by increasing stability as well $[6,9,144]$. ALC and LA are not micronutrients, as they are made in the mitochondria, but they are illustrative of many normal metabolites that may be useful in the elderly.

\section{Conclusion}

The work on acetyl carnitine and lipoic acid suggests that decay of mitochondria leading to cancer and a variety of other diseases of aging is not inevitable but can be delayed by various interventions to improve metabolism. Understanding the mechanisms will suggest still other interventions. For example, if the effectiveness of lipoic acid is because it induces the $\sim 200$ enzymes in the phase- 2 defense system against oxidants, as seems likely, then the whole area of optimizing our various inducible defense systems for longevity by hormetic mechanisms becomes attractive and we are at the start of the discovery of many interventions.

If the triage hypothesis proves to be correct, as the vita$\min \mathrm{K}$ analysis suggests, it will demonstrate the importance for a long and healthy life of avoiding modest micronutrient deficiencies for minimizing cancer and other age-related diseases, and for changing how people think about nutrition and health. Most of the world's population, including that of the US, is inadequate in one or more micronutrients according to current intake recommendations. Yet, because there is no overt pathology associated with these levels of deficiency, there has been little public concern. The triage hypothesis framework may facilitate the discovery of sensitive and specific biomarkers of micronutrient insufficiencies that can be used to optimize metabolism at a personal and population level. Current recommendations do not take into account the insidious biochemical consequences of metabolic triage. We think that we can show that insidious damage is indeed occurring at modest levels of deficiency and that this damage will increase the risk of cancer, cardiovascular disease, cognitive dysfunction, and the other diseases associated with aging.

The genomic variability between individuals is being explored at a rapid rate, but a correct understanding as to how to intervene awaits bringing nutrition, particularly micronutrient-dependent proteins into the picture. We believe that the analysis of binding constants is the beginning of a large field that will make it possible to overcome a large class of deleterious genetic changes by nutritional interventions. 
Various lines of evidence reviewed here suggest that healthier lives are to be gained by optimizing our metabolism. More attention to balanced diets and optimizing micronutrient intake could have a major effect on delaying the degenerative diseases of aging. My vision is that this will be done in the future by individuals measuring their own levels of micronutrients from a finger prick of blood in a machine in their local pharmacy (http:// www.reliadiagnostics.com/), and tuning up their metabolism by adjusting diet or taking supplements - the beginning of an age of true preventive medicine.

\section{Conflict of Interest}

Dr. Ames is one of the founders of Juvenon (http:// juvenon.com/), a company that has licensed the University of California patent on acetyl carnitine + lipoic acid for rejuvenating old mitochondria (Ames and T. Hagen, inventors), sells acetyl carnitine + lipoic acid supplements, and does clinical trials on them. Ames founder's stock was put in a nonprofit foundation at the founding in 1999. He is director of Juvenon's Scientific Advisory Board, but reimbursement for that from Juvenon is given to the foundation.

\section{Acknowledgments}

The author is indebted to J. McCann, D. Killilea, S. Shenvi, and J. Suh for helpful criticisms and to the many excellent students and colleagues who have contributed to this work. This paper has been adapted in part from [26].

\section{References}

[1] M. K. Shigenaga, T. M. Hagen, and B. N. Ames, "Oxidative damage and mitochondrial decay in aging," Proceedings of the National Academy of Sciences of the United States of America, vol. 91, no. 23, pp. 10771-10778, 1994.

[2] K. B. Beckman and B. N. Ames, "Mitochondrial aging: open questions," Annals of the New York Academy of Sciences, vol. 854, pp. 118-127, 1998.

[3] L. J. Marnett, H. K. Hurd, M. C. Hollstein, D. E. Levin, H. Esterbauer, and B. N. Ames, "Naturally occurring carbonyl compounds are mutagens in Salmonella tester strain TA104," Mutation Research, vol. 148, no. 1-2, pp. 25-34, 1985.

[4] T. Douki and B. N. Ames, "An HPLC-EC assay for 1,N2propano adducts of 2'-deoxyguanosine with 4 - hydroxynonenal and other $\alpha, \beta$-unsaturated aldehydes," Chemical Research in Toxicology, vol. 7, no. 4, pp. 511-518, 1994.

[5] A. M. S. Lezza, F. P. Fallacara, V. Pesce, C. Leeuwenburgh, P. Cantatore, and M. N. Gadaleta, "Localization of abasic sites and single-strand breaks in mitochondrial DNA from brain of aged rat, treated or not with caloric restriction diet," Neurochemical Research, vol. 33, no. 12, pp. 2609-2614, 2008.

[6] T. M. Hagen, J. Liu, J. Lykkesfeldt et al., "Feeding acetyl-L-carnitine and lipoic acid to old rats significantly improves metabolic function while decreasing oxidative stress," Proceedings of the National Academy of Sciences of the United States of America, vol. 99, no. 4, pp. 1870-1875, 2002.
[7] T. M. Hagen, R. Moreau, J. H. Suh, and F. Visioli, "Mitochondrial decay in the aging rat heart: evidence for improvement by dietary supplementation with acetyl-L-carnitine and/or lipoic acid," Annals of the New York Academy of Sciences, vol. 959, pp. 491-507, 2002.

[8] J. Liu, E. Head, A. M. Gharib et al., "Memory loss in old rats is associated with brain mitochondrial decay and RNA/DNA oxidation: partial reversal by feeding acetyl-Lcarnitine and/or R- $\alpha$-lipoic acid," Proceedings of the National Academy of Sciences of the United States of America, vol. 99, no. 4, pp. 2356-2361, 2002.

[9] J. Liu, D. W. Killilea, and B. N. Ames, "Age-associated mitochondrial oxidative decay: improvement of carnitine acetyltransferase substrate-binding affinity and activity in brain by feeding old rats acetyl-L-carnitine and/or R- $\alpha$-lipoic acid," Proceedings of the National Academy of Sciences of the United States of America, vol. 99, no. 4, pp. 1876-1881, 2002.

[10] B. N. Ames, J. Liu, H. Atamna, and T. M. Hagen, "Delaying the mitochondrial decay of aging in the brain," Clinical Neuroscience Research, vol. 2, no. 5-6, pp. 331-338, 2003.

[11] M. Manczak, Y. Jung, B. S. Park, D. Partovi, and P. H. Reddy, "Time-course of mitochondrial gene expressions in mice brains: implications for mitochondrial dysfunction, oxidative damage, and cytochrome c in aging," Journal of Neurochemistry, vol. 92, no. 3, pp. 494-504, 2005.

[12] J. H. Suh, S.-H. Heath, and T. M. Hagen, "Two subpopulations of mitochondria in the aging rat heart display heterogenous levels of oxidative stress," Free Radical Biology and Medicine, vol. 35, no. 9, pp. 1064-1072, 2003.

[13] M. N. Gadaleta, A. Cormio, V. Pesce, A. M. S. Lezza, and P. Cantatore, "Aging and mitochondria," Biochimie, vol. 80, no. 10, pp. 863-870, 1998.

[14] M. N. Gadaleta, V. Petruzzella, M. Renis, F. Fracasso, and P. Cantatote, "Reduced transcription of mitochondrial DNA in the senescent rat. Tissue dependence and effect of Lcarnitine," European Journal of Biochemistry, vol. 187, no. 3, pp. 501-506, 1990.

[15] T. M. Hagen, R. T. Ingersoll, C. M. Wehr et al., "AcetylL-carnitine fed to old rats partially restores mitochondrial function and ambulatory activity," Proceedings of the National Academy of Sciences of the United States of America, vol. 95, no. 16, pp. 9562-9566, 1998.

[16] T. M. Hagen, R. T. Ingersoll, J. Lykkesfeldt et al., “( $R)-\alpha-$ lipoic acid-supplemented old rats have improved mitochondrial function, decreased oxidative damage, and increased metabolic rate," FASEB Journal, vol. 13, no. 2, pp. 411-418, 1999.

[17] R. Gatti, C. B. de Palo, P. Spinella, and E. F. de Palo, "Free carnitine and acetyl carnitine plasma levels and their relationship with body muscular mass in athletes," Amino Acids, vol. 14, no. 4, pp. 361-369, 1998.

[18] J. H. Suh, S. V. Shenvi, B. M. Dixon et al., "Decline in transcriptional activity of Nrf2 causes age-related loss of glutathione synthesis, which is reversible with lipoic acid," Proceedings of the National Academy of Sciences of the United States of America, vol. 101, no. 10, pp. 3381-3386, 2004.

[19] J. H. Suh, H. Wang, R.-M. Liu, J. Liu, and T. M. Hagen, " $(R)$ - $\alpha$-lipoic acid reverses the age-related loss in GSH redox status in post-mitotic tissues: evidence for increased cysteine requirement for GSH synthesis," Archives of Biochemistry and Biophysics, vol. 423, no. 1, pp. 126-135, 2004. 
[20] A. R. Smith, S. V. Shenvi, M. Widlansky, J. H. Suh, and T. M. Hagen, "Lipoic acid as a potential therapy for chronic diseases associated with oxidative stress," Current Medicinal Chemistry, vol. 11, no. 9, pp. 1135-1146, 2004.

[21] M.-K. Kwak, N. Wakabayashi, K. Itoh, H. Motohashi, M. Yamamoto, and T. W. Kensler, "Modulation of gene expression by cancer chemopreventive dithiolethiones through the Keap1-Nrf2 pathway: identification of novel gene clusters for cell survival," Journal of Biological Chemistry, vol. 278, no. 10, pp. 8135-8145, 2003.

[22] N. Wakabayashi, A. T. Dinkova-Kostova, W. D. Holtzclaw et al., "Protection against electrophile and oxidant stress by induction of the phase 2 response: fate of cysteines of the Keap1 sensor modified by inducers," Proceedings of the National Academy of Sciences of the United States of America, vol. 101, no. 7, pp. 2040-2045, 2004.

[23] S.-K. Park, K. Kim, G. P. Page, D. B. Allison, R. Weindruch, and T. A. Prolla, "Gene expression profiling of aging in multiple mouse strains: identification of aging biomarkers and impact of dietary antioxidants," Aging Cell, vol. 8, no. 4, pp. 484-495, 2009.

[24] B. N. Ames, "A theory of evolutionary allocation of scarce micronutrients by enzyme triage: adequate micronutrient nutrition to delay the degenerative diseases of aging," Proceedings of the National Academy of Sciences of the United States of America, vol. 103, pp. 17589-17594, 2006.

[25] B. N. Ames and J. C. McCann, "Foreword: prevention of cancer, and the other degenerative diseases of aging, through nutrition," in Chemoprevention of Cancer and DNA Damage by Dietary Factors, S. Knasmüller, D. DeMarini, I. Johnson, and C. Gerhäuser, Eds., Wiley-VCH, Weinheim, Germany, 2009.

[26] B. N. Ames, "Optimal micronutrients delay mitochondrial decay and age-associated diseases ," Mechanisms of Ageing and Development, vol. 131, no. 7-8, pp. 473-479, 2010.

[27] T. B. L. Kirkwood, "Understanding ageing from an evolutionary perspective," Journal of Internal Medicine, vol. 263, no. 2, pp. 117-127, 2008.

[28] S. B. Eaton and M. Konner, "Paleolithic nutrition. A consideration of its nature and current implications," New England Journal of Medicine, vol. 312, no. 5, pp. 283-289, 1985.

[29] J. C. McCann and B. N. Ames, "Is there convincing biological or behavioral evidence linking vitamin D deficiency to brain dysfunction?" FASEB Journal, vol. 22, no. 4, pp. 982-1001, 2008.

[30] J. C. McCann and B. N. Ames, "Vitamin K, an example of triage theory: is micronutrient inadequacy linked to diseases of aging?" American Journal of Clinical Nutrition, vol. 90, no. 4, pp. 889-907, 2009.

[31] A. Moshfegh, J. Goldman, and L. Cleveland, "What We Eat in America, NHANES 2001-2002: Usual Nutrient Intakes from Food Compared to Dietary Reference Intakes," U.S. Department of Agriculture, Agricultural Research Service, 2005.

[32] Y. J. Hung, C. H. Lee, N. F. Chu, and Y. S. Shieh, "Plasma protein growth arrest-specific 6 levels are associated with altered glucose tolerance, inflammation, and endothelial dysfunction," Diabetes Care, vol. 33, no. 8, pp. 1840-1844, 2010.

[33] R. J. Rennenberg, P. W. de Leeuw, A. G. H. Kessels et al., "Calcium scores and matrix Gla protein levels: association with vitamin K status," European Journal of Clinical Investigation, vol. 40, no. 4, pp. 344-349, 2010.
[34] R. J. Rennenberg, B. J. van Varik, L. J. Schurgers et al., "Chronic coumarin treatment is associated with increased extracoronary arterial calcification in humans," Blood, vol. 115, no. 24, pp. 5121-5123, 2010.

[35] T. V. Tkatchenko, R. A. Moreno-Rodriguez, S. J. Conway, J. D. Molkentin, R. R. Markwald, and A. V. Tkatchenko, "Lack of periostin leads to suppression of Notch1 signaling and calcific aortic valve disease," Physiological Genomics, vol. 39, no. 3, pp. 160-168, 2009.

[36] Y. Zhang, G. Wen, G. Shao et al., "TGFBI deficiency predisposes mice to spontaneous tumor development," Cancer Research, vol. 69, no. 1, pp. 37-44, 2009.

[37] K. Nimptsch, S. Rohrmann, A. Nieters, and J. Linseisen, "Serum undercarboxylated osteocalcin as biomarker of vitamin $\mathrm{K}$ intake and risk of prostate cancer: a nested casecontrol study in the Heidelberg cohort of the European prospective investigation into cancer and nutrition," Cancer Epidemiology Biomarkers and Prevention, vol. 18, no. 1, pp. 49-56, 2009.

[38] C. Courtemanche, A. C. Huang, I. Elson-Schwab, N. Kerry, B. Y. Ng, and B. N. Ames, "Folate deficiency and ionizing radiation cause DNA breaks in primary human lymphocytes: a comparison," FASEB Journal, vol. 18, no. 1, pp. 209-211, 2004.

[39] H. Atamna, J. Newberry, R. Erlitzki, C. S. Schultz, and B. N. Ames, "Biotin deficiency inhibits heme synthesis and impairs mitochondria in human lung fibroblasts," Journal of Nutrition, vol. 137, no. 1, pp. 25-30, 2007.

[40] P. B. Walter, M. D. Knutson, A. Paler-Martinez et al., "Iron deficiency and iron excess damage mitochondria and mitochondrial DNA in rats," Proceedings of the National Academy of Sciences of the United States of America, vol. 99, no. 4, pp. 2264-2269, 2002.

[41] D. W. Killilea and B. N. Ames, "Magnesium deficiency accelerates cellular senescence in cultured human fibroblasts," Proceedings of the National Academy of Sciences of the United States of America, vol. 105, no. 15, pp. 5768-5773, 2008.

[42] E. Ho and B. N. Ames, "Low intracellular zinc induces oxidative DNA damage, disrupts $\mathrm{p} 53, \mathrm{NF} \kappa \mathrm{B}$, and AP1 DNA binding, and affects DNA repair in a rat glioma cell line," Proceedings of the National Academy of Sciences of the United States of America, vol. 99, no. 26, pp. 16770-16775, 2002.

[43] J. T. MacGregor, R. Schlegel, C. M. Wehr, P. Alperin, and B. N. Ames, "Cytogenetic damage induced by folate deficiency in mice is enhanced by caffeine," Proceedings of the National Academy of Sciences of the United States of America, vol. 87, no. 24, pp. 9962-9965, 1990.

[44] E. Knock, L. Deng, Q. Wu, A. K. Lawrance, X.-L. Wang, and R. Rozen, "Strain differences in mice highlight the role of DNA damage in neoplasia induced by low dietary folate," Journal of Nutrition, vol. 138, no. 4, pp. 653-658, 2008.

[45] C. Courtemanche, I. Elson-Schwab, S. T. Mashiyama, N. Kerry, and B. N. Ames, "Folate deficiency inhibits the proliferation of primary human $\mathrm{CD} 8+\mathrm{T}$ lymphocytes in vitro," Journal of Immunology, vol. 173, no. 5, pp. 3186-3192, 2004.

[46] S. T. Mashiyama, C. M. Hansen, E. Roitman et al., "An assay for uracil in human DNA at baseline: effect of marginal vitamin B6 deficiency," Analytical Biochemistry, vol. 372, no. 1, pp. 21-31, 2008. 
[47] B. C. Blount, M. M. Mack, C. M. Wehr et al., "Folate deficiency causes uracil misincorporation into human DNA and chromosome breakage: implications for cancer and neuronal damage," Proceedings of the National Academy of Sciences of the United States of America, vol. 94, no. 7, pp. 3290-3295, 1997.

[48] M. Fenech, "The Genome Health Clinic and Genome Health Nutrigenomics concepts: diagnosis and nutritional treatment of genome and epigenome damage on an individual basis," Mutagenesis, vol. 20, no. 4, pp. 255-269, 2005.

[49] P. Leopardi, F. Marcon, S. Caiola et al., "Effects of folic acid deficiency and MTHFR C677T polymorphism on spontaneous and radiation-induced micronuclei in human lymphocytes," Mutagenesis, vol. 21, no. 5, pp. 327-333, 2006.

[50] J. Ni, L. Lu, M. Fenech, and X. Wang, "Folate deficiency in human peripheral blood lymphocytes induces chromosome 8 aneuploidy but this effect is not modified by riboflavin," Environmental and Molecular Mutagenesis, vol. 51, no. 1, pp. 15-22, 2010.

[51] S. J. Duthie, G. Grant, L. P. Pirie, A. J. Watson, and G. P. Margison, "Folate deficiency alters hepatic and colon MGMT and OGG-1 DNA repair protein expression in rats but has no effect on genome-wide DNA methylation," Cancer Prevention Research, vol. 3, no. 1, pp. 92-100, 2010.

[52] R. B. Everson, C. M. Wehr, G. L. Erexson, and J. T. MacGregor, "Association of marginal folate depletion with increased human chromosomal damage in vivo: demonstration by analysis of micronucleated erythrocytes," Journal of the National Cancer Institute, vol. 80, no. 7, pp. 525-529, 1988.

[53] J. T. MacGregor, C. M. Wehr, R. A. Hiatt et al., "'Spontaneous' genetic damage in man: evaluation of interindividual variability, relationship among markers of damage, and influence of nutritional status," Mutation Research, vol. 377, no. 1, pp. 125-135, 1997.

[54] E. Murgia, M. Ballardin, S. Bonassi, A. M. Rossi, and R. Barale, "Validation of micronuclei frequency in peripheral blood lymphocytes as early cancer risk biomarker in a nested case-control study," Mutation Research, vol. 639, no. 1-2, pp. 27-34, 2008.

[55] M. F. Fenech, I. E. Dreosti, and J. R. Rinaldi, "Folate, vitamin B12, homocysteine status and chromosome damage rate in lymphocytes of older men," Carcinogenesis, vol. 18, no. 7, pp. 1329-1336, 1997.

[56] M. F. Fenech, "Dietary reference values of individual micronutrients and nutriomes for genome damage prevention: current status and a road map to the future," American Journal of Clinical Nutrition, vol. 91, no. 5, pp. 1438S-1454S, 2010.

[57] B. N. Ames and P. Wakimoto, "Are vitamin and mineral deficiencies a major cancer risk?" Nature Reviews Cancer, vol. 2, no. 9, pp. 694-704, 2002.

[58] A. J. Levine, J. C. Figueiredo, W. Lee et al., "A candidate gene study of folate-associated one carbon metabolism genes and colorectal cancer risk," Cancer Epidemiology Biomarkers and Prevention, vol. 19, no. 7, pp. 1812-1821, 2010.

[59] E. S. Ford, "Race, education, and dietary cations: findings from the third national health and nutrition examination survey," Ethnicity and Disease, vol. 8, no. 1, pp. 10-20, 1998.

[60] C. H. Fox, M. C. Mahoney, D. Ramsoomair, and C. A. Carter, "Magnesium deficiency in African-Americans: does it contribute to increased cardiovascular risk factors?" Journal of the National Medical Association, vol. 95, no. 4, pp. 257262, 2003.
[61] "Data Tables: Food and Nutrient Intakes by Income, 19941996," U.S. Department of Agriculture, Agricultural Research Services, 1999, http://www.ars.usda.gov/ba/bhnrc/ndl.

[62] M. P. Vaquero, "Magnesium and trace elements in the elderly: intake, status and recommendations," Journal of Nutrition, Health and Aging, vol. 6, no. 2, pp. 147-153, 2002.

[63] P. Wakimoto and G. Block, "Dietary intake, dietary patterns, and changes with age: an epidemiological perspective," Journals of Gerontology A, vol. 56, no. 2, pp. 65-80, 2001.

[64] A. Hartwig, "Role of magnesium in genomic stability," Mutation Research, vol. 475, no. 1-2, pp. 113-121, 2001.

[65] J. M. Blondell, "The anticarcinogenic effect of magnesium," Medical Hypotheses, vol. 6, no. 8, pp. 863-871, 1980.

[66] A. R. Folsom and C.-P. Hong, "Magnesium intake and reduced risk of colon cancer in a prospective study of women," American Journal of Epidemiology, vol. 163, no. 3, pp. 232-235, 2006.

[67] K. He, K. Liu, M. L. Daviglus et al., "Magnesium intake and incidence of metabolic syndrome among young adults," Circulation, vol. 113, no. 13, pp. 1675-1682, 2006.

[68] S. C. Larsson, L. Bergkvist, and A. Wolk, "Magnesium intake in relation to risk of colorectal cancer in women," Journal of the American Medical Association, vol. 293, no. 1, pp. 86-89, 2005.

[69] N. Leone, D. Courbon, P. Ducimetiere, and M. Zureik, "Zinc, copper, and magnesium and risks for all-cause, cancer, and cardiovascular mortality," Epidemiology, vol. 17, no. 3, pp. 308-314, 2006.

[70] Institute of Medicine, Committee on the Scientific Evaluation of Dietary Reference Intakes, Food and Nutrition Board, National Academy of Sciences, National Academy Press, Washington, DC, USA, 1997.

[71] R. M. van Dam, F. B. Hu, L. Rosenberg, S. Krishnan, and J. R. Palmer, "Dietary calcium and magnesium, major food sources, and risk of type 2 diabetes in U.S. black women," Diabetes Care, vol. 29, no. 10, pp. 2238-2243, 2006.

[72] S. C. Larsson, M. J. Virtanen, M. Mars et al., "Magnesium, calcium, potassium, and sodium intakes and risk of stroke in male smokers," Archives of Internal Medicine, vol. 168, no. 5, pp. 459-465, 2008.

[73] L. T. Bell, M. Branstrator, C. Roux, and L. S. Hurley, "Chromosomal abnormalities in maternal and fetal tissues of magnesium or zinc deficient rats," Teratology, vol. 12, no. 3, pp. 221-226, 1975.

[74] D. Blache, S. Devaux, O. Joubert et al., "Long-term moderate magnesium-deficient diet shows relationships between blood pressure, inflammation and oxidant stress defense in aging rats," Free Radical Biology and Medicine, vol. 41, no. 2, pp. 277-284, 2006.

[75] S. C. Larsson, N. Orsini, and A. Wolk, "Vitamin B6 and risk of colorectal cancer: a meta-analysis of prospective studies," Journal of the American Medical Association, vol. 303, no. 11, pp. 1077-1083, 2010.

[76] M. Johansson, C. Relton, P. M. Ueland et al., "Serum B vitamin levels and risk of lung cancer," Journal of the American Medical Association, vol. 303, no. 23, pp. 23772385, 2010.

[77] S. J. P. M. Eussen, S. E. Vollset, S. Hustad et al., "Vitamins $\mathrm{B} 2$ and B6 and genetic polymorphisms related to one-carbon metabolism as risk factors for gastric adenocarcinoma in the European Prospective Investigation into Cancer and Nutrition," Cancer Epidemiology Biomarkers and Prevention, vol. 19, no. 1, pp. 28-38, 2010. 
[78] K. Matsubara, S.-I. Komatsu, T. Oka, and N. Kato, "Vitamin B6-mediated suppression of colon tumorigenesis, cell proliferation, and angiogenesis," Journal of Nutritional Biochemistry, vol. 14, no. 5, pp. 246-250, 2003.

[79] M. S. Morris, M. F. Picciano, P. F. Jacques, and J. Selhub, "Plasma pyridoxal 5 '-phosphate in the US population: the National Health and Nutrition Examination Survey, 20032004," American Journal of Clinical Nutrition, vol. 87, no. 5, pp. 1446-1454, 2008.

[80] A.-M. Hvas, S. Juul, P. Bech, and E. Nexø, "Vitamin B6 level is associated with symptoms of depression," Psychotherapy and Psychosomatics, vol. 73, no. 6, pp. 340-343, 2004.

[81] P. J. Kelly, V. E. Shih, J. P. Kistler et al., "Low vitamin B6 but not homocyst(e)ine is associated with increased risk of stroke and transient ischemic attack in the era of folic acid grain fortification," Stroke, vol. 34, no. 6, pp. e51-e54, 2003.

[82] D. F. Smith, J. T. MacGregor, R. A. Hiatt et al., "Micronucleated erythrocytes as an index of cytogenetic damages in humans: demographic and dietary factors associated with micronucleated erythrocytes in splenectomized subjects," Cancer Research, vol. 50, no. 16, pp. 5049-5054, 1990.

[83] M. F. Holick, "Vitamin D: its role in cancer prevention and treatment," Progress in Biophysics and Molecular Biology, vol. 92, no. 1, pp. 49-59, 2006.

[84] J. Ishihara, T. Otani, M. Inoue, M. Iwasaki, S. Sasazuki, and S. Tsugane, "Low intake of vitamin B-6 is associated with increased risk of colorectal cancer in Japanese men," Journal of Nutrition, vol. 137, no. 7, pp. 1808-1814, 2007.

[85] M. V. Grau, J. A. Baron, R. S. Sandler et al., "Prolonged effect of calcium supplementation on risk of colorectal adenomas in a randomized trial," Journal of the National Cancer Institute, vol. 99, no. 2, pp. 129-136, 2007.

[86] J. E. Chavarro, M. J. Stampfer, H. Li, H. Campos, T. Kurth, and J. Ma, "A prospective study of polyunsaturated fatty acid levels in blood and prostate cancer risk," Cancer Epidemiology Biomarkers and Prevention, vol. 16, no. 7, pp. 1364-1370, 2007.

[87] Q. Dai, M. J. Shrubsole, R. M. Ness et al., "The relation of magnesium and calcium intakes and a genetic polymorphism in the magnesium transporter to colorectal neoplasia risk," American Journal of Clinical Nutrition, vol. 86, no. 3, pp. 743751, 2007.

[88] R. B. Franklin and L. C. Costello, "Zinc as an anti-tumor agent in prostate cancer and in other cancers," Archives of Biochemistry and Biophysics, vol. 463, no. 2, pp. 211-217, 2007.

[89] C. C. Abnet, B. Lai, Y.-L. Qiao et al., "Zinc concentration in esophageal biopsy specimens measured by X-ray fluorescence and esophageal cancer risk," Journal of the National Cancer Institute, vol. 97, no. 4, pp. 301-306, 2005.

[90] L. Y. Y. Fong, Y. Jiang, and J. L. Farber, "Zinc deficiency potentiates induction and progression of lingual and esophageal tumors in p53-deficient mice," Carcinogenesis, vol. 27, no. 7, pp. 1489-1496, 2006.

[91] A. S. Jaiswal and S. Narayan, "Zinc stabilizes adenomatous polyposis coli (APC) protein levels and induces cell cycle arrest in colon cancer cells," Journal of Cellular Biochemistry, vol. 93, no. 2, pp. 345-357, 2004.

[92] A. S. Prasad, F. W. J. Beck, T. D. Doerr et al., "Nutritional and zinc status of head and neck cancer patients: an interpretive review," Journal of the American College of Nutrition, vol. 17, no. 5, pp. 409-418, 1998.
[93] K.-Y. Liaw, P.-H. Lee, F.-C. Wu, J.-S. Tsai, and S.-Y. Lin-Shiau, "Zinc, copper, and superoxide dismutase in hepatocellular carcinoma," American Journal of Gastroenterology, vol. 92, no. 12, pp. 2260-2263, 1997.

[94] M. Fenech, C. Aitken, and J. Rinaldi, "Folate, vitamin B12, homocysteine status and DNA damage in young Australian adults," Carcinogenesis, vol. 19, no. 7, pp. 1163-1171, 1998.

[95] Y. I. Goh, E. Bollano, T. R. Einarson, and G. Koren, "Prenatal multivitamin supplementation and rates of pediatric cancers: a meta-analysis," Clinical Pharmacology and Therapeutics, vol. 81, no. 5, pp. 685-691, 2007.

[96] M. L. Ribeiro, D. P. Arçari, A. C. Squassoni, and J. Pedrazzoli Jr., "Effects of multivitamin supplementation on DNA damage in lymphocytes from elderly volunteers," Mechanisms of Ageing and Development, vol. 128, no. 10, pp. 577-580, 2007.

[97] J. C. McCann and B. N. Ames, "Evidence required for causal inferences about effects of micronutrient deficiencies during development on brain health-DHA, choline, iron, and vitamin D," in Micronutrients and Brain Health, L. Packer, H. Sies, M. Eggersdorfer, and E. Cadenas, Eds., chapter 30, CRC Press, London, UK, 2009.

[98] B. N. Ames, J. C. McCann, M. J. Stampfer, and W. C. Willett, "Evidence-based decision making on micronutrients and chronic disease: long-term randomized controlled trials are not enough," American Journal of Clinical Nutrition, vol. 86, no. 2, pp. 522-524, 2007.

[99] B. N. Ames, "Increasing longevity by tuning up metabolism," EMBO Reports, vol. 6, no. 1, pp. S20-S24, 2005.

[100] B. N. Ames, H. Atamna, and D. W. Killilea, "Mineral and vitamin deficiencies can accelerate the mitochondrial decay of aging," Molecular Aspects of Medicine, vol. 26, no. 4-5, pp. 363-378, 2005.

[101] D. A. Richert and M. P. Schulman, "Vitamin interrelationships in heme synthesis," American Journal of Clinical Nutrition, vol. 7, pp. 416-425, 1959.

[102] H. Atamna, "Heme, iron, and the mitochondrial decay of ageing," Ageing Research Reviews, vol. 3, no. 3, pp. 303-318, 2004.

[103] H. Atamna, J. Liu, and B. N. Ames, "Heme deficiency selectively interrupts assembly of mitochondrial complex IV in human fibroblasts: relevance to aging," Journal of Biological Chemistry, vol. 276, no. 51, pp. 48410-48416, 2001.

[104] World Health Organization, Iron Deficiency Anaemia: Assessment, Prevention, and Control. A Guide for Programme Managers, World Health Organization, Geneva, Switzerland, 2001.

[105] K. G. Nead, J. S. Halterman, J. M. Kaczorowski, P. Auinger, and M. Weitzman, "Overweight children and adolescents: a risk group for iron deficiency," Pediatrics, vol. 114, no. 1, pp. 104-108, 2004.

[106] J. C. McCann and B. N. Ames, "DHA and cognitive development," Pediatric Basics, vol. 117, pp. 16-22, 2007.

[107] J. L. Beard and J. R. Connor, "Iron status and neural functioning," Annual Review of Nutrition, vol. 23, pp. 41-58, 2003.

[108] S. Grantham-McGregor and C. Ani, "A review of studies on the effect of iron deficiency on cognitive development in children," Journal of Nutrition, vol. 131, no. 2, supplement 2, pp. 649S-668S, 2001.

[109] E. K. Hurtado, A. H. Claussen, and K. G. Scott, "Early childhood anemia and mild or moderate mental retardation," American Journal of Clinical Nutrition, vol. 69, no. 1, pp. 115119, 1999. 
[110] B. Lozoff, E. Jimenez, J. Hagen, E. Mollen, and A. W. Wolf, "Poorer behavioral and developmental outcome more than 10 years after treatment for iron deficiency in infancy," Pediatrics, vol. 105, no. 4, article E51, 2000.

[111] H. Atamna, D. W. Killilea, A. N. Killilea, and B. N. Ames, "Heme deficiency may be a factor in the mitochondrial and neuronal decay of aging," Proceedings of the National Academy of Sciences of the United States of America, vol. 99, no. 23, pp. 14807-14812, 2002.

[112] M. DeUngria, R. Rao, J. D. Wobken, M. Luciana, C. A. Nelson, and M. K. Georgieff, "Perinatal iron deficiency decreases cytochrome $\mathrm{c}$ oxidase (CytOx) activity in selected regions of neonatal rat brain," Pediatric Research, vol. 48, no. 2, pp. 169-176, 2000.

[113] M. B. Youdim and S. Yehuda, "The neurochemical basis of cognitive deficits induced by brain iron deficiency: involvement of dopamine-opiate system," Cellular and Molecular Biology, vol. 46, no. 3, pp. 491-500, 2000.

[114] M. L. Failla, "Trace elements and host defense: recent advances and continuing challenges," Journal of Nutrition, vol. 133, no. 5, pp. 1443S-1447S, 2003.

[115] F. E. Viteri and H. Gonzalez, "Adverse outcomes of poor micronutrient status in childhood and adolescence," Nutrition Reviews, vol. 60, no. 5, pp. S77-S83, 2002.

[116] P. R. Dallman, "Biochemical basis for the manifestations of iron deficiency," Annual Review of Nutrition, vol. 6, pp. 1340, 1986.

[117] U. M. Chockalingam, E. Murphy, J. C. Ophoven, S. A. Weisdorf, and M. K. Georgieff, "Cord transferrin and ferritin values in newborn infants at risk for prenatal uteroplacental insufficiency and chronic hypoxia," Journal of Pediatrics, vol. 111, no. 2, pp. 283-286, 1987.

[118] R. Rao and M. K. Georgieff, "Perinatal aspects of iron metabolism," Acta Paediatrica, vol. 91, no. 438, pp. 124-129, 2002.

[119] S. F. Guiang III, M. K. Georgieff, D. J. Lambert, R. L. Schmidt, and J. A. Widness, "Intravenous iron supplementation effect on tissue iron and hemoproteins in chronically phlebotomized lambs," American Journal of Physiology, vol. 273, no. 6, pp. R2124-R2131, 1997.

[120] T. D. Brutsaert, S. Hernandez-Cordero, J. Rivera, T. Viola, G. Hughes, and J. D. Haas, "Iron supplementation improves progressive fatigue resistance during dynamic knee extensor exercise in iron-depleted, nonanemic women," American Journal of Clinical Nutrition, vol. 77, no. 2, pp. 441-448, 2003.

[121] S. Hercberg, C. Estaquio, S. Czernichow et al., "Iron status and risk of cancers in the SU.VI.MAX cohort," Journal of Nutrition, vol. 135, no. 11, pp. 2664-2668, 2005.

[122] D. Pra, S. I. Rech Franke, J. A. Pegas Henriques, and M. Fenech, "A possible link between iron deficiency and gastrointestinal carcinogenesis," Nutrition and Cancer, vol. 61, no. 4, pp. 415-426, 2009.

[123] M. Elmberg, R. Hultcrantz, A. Ekbom et al., "Cancer risk in patients with hereditary hemochromatosis and in their firstdegree relatives," Gastroenterology, vol. 125, no. 6, pp. 1733$1741,2003$.

[124] D. W. Killilea, H. Atamna, C. Liao, and B. N. Ames, "Iron accumulation during cellular senescence in human fibroblasts in vitro," Antioxidants and Redox Signaling, vol. 5, no. 5, pp. 507-516, 2003.

[125] A. Y. Seo, J. Xu, S. Servais et al., "Mitochondrial iron accumulation with age and functional consequences," Aging Cell, vol. 7, no. 5, pp. 706-716, 2008.
[126] A. Lal, W. Atamna, D. W. Killilea, J. H. Suh, and B. N. Ames, "Lipoic acid and acetyl-carnitine reverse iron-induced oxidative stress in human fibroblasts," Redox Report, vol. 13, no. 1, pp. 2-10, 2008.

[127] E. Ho, C. Courtemanche, and B. N. Ames, "Zinc deficiency induces oxidative DNA damage and increases P53 expression in human lung fibroblasts," Journal of Nutrition, vol. 133, no. 8, pp. 2543-2548, 2003.

[128] P. I. Oteiza, M. S. Clegg, M. P. Zago, and C. L. Keen, “Zinc deficiency induces oxidative stress and AP-1 activation in 3T3 cells," Free Radical Biology and Medicine, vol. 28, no. 7, pp. 1091-1099, 2000.

[129] L. Y. Y. Fong, L. Zhang, Y. Jiang, and J. L. Farber, "Dietary zinc modulation of COX-2 expression and lingual and esophageal carcinogenesis in rats," Journal of the National Cancer Institute, vol. 97, no. 1, pp. 40-50, 2005.

[130] E. K. Jaffe, "The porphobilinogen synthase catalyzed reaction mechanism," Bioorganic Chemistry, vol. 32, no. 5, pp. 316325, 2004.

[131] D. M. Mock, "Marginal biotin deficiency is teratogenic in mice and perhaps humans: a review of biotin deficiency during human pregnancy and effects of biotin deficiency on gene expression and enzyme activities in mouse dam and fetus," Journal of Nutritional Biochemistry, vol. 16, no. 7, pp. 435-437, 2005.

[132] D. M. Mock, Biotin. Present Knowledge in Nutrition, ILSI Press, Washington, DC, USA, 7th edition, 1996.

[133] S. L. Stratton, A. Bogusiewicz, M. M. Mock, N. I. Mock, A. M. Wells, and D. M. Mock, "Lymphocyte propionyl-CoA carboxylase and its activation by biotin are sensitive indicators of marginal biotin deficiency in humans," American Journal of Clinical Nutrition, vol. 84, no. 2, pp. 384-388, 2006.

[134] D. J. Waters, S. Shen, L. T. Glickman et al., "Prostate cancer risk and DNA damage: translational significance of selenium supplementation in a canine model," Carcinogenesis, vol. 26, no. 7, pp. 1256-1262, 2005.

[135] J. Wu, G. H. Lyons, R. D. Graham, and M. F. Fenech, "The effect of selenium, as selenomethionine, on genome stability and cytotoxicity in human lymphocytes measured using the cytokinesis-block micronucleus cytome assay," Mutagenesis, vol. 24, no. 3, pp. 225-232, 2009.

[136] M. Ebbing, K. H. Bønaa, O. Nygård et al., "Cancer incidence and mortality after treatment with folic acid and vitamin B12," Journal of the American Medical Association, vol. 302, no. 19 , pp. 2119-2126, 2009.

[137] C. M. Ulrich and J. D. Potter, "Folate and cancer-timing is everything," Journal of the American Medical Association, vol. 297, no. 21, pp. 2408-2409, 2007.

[138] C. Ma, Y. Rong, D. R. Radiloff et al., "Extracellular matrix protein $\beta$ ig-h3/TGFBI promotes metastasis of colon cancer by enhancing cell extravasation," Genes and Development, vol. 22, no. 3, pp. 308-321, 2008.

[139] B. N. Ames, I. Elson-Schwab, and E. A. Silver, "Highdose vitamin therapy stimulates variant enzymes with decreased coenzyme binding affinity (increased $\mathrm{Km}$ ): relevance to genetic disease and polymorphisms," American Journal of Clinical Nutrition, vol. 75, no. 4, pp. 616-658, 2002.

[140] B. N. Ames, J. H. Suh, and J. Liu, "Enzymes lose binding affinity (increase $\mathrm{Km}$ ) for coenzymes and substrates with age: a strategy for remediation," in Nutrigenomics: Discovering the Path to Personalized Nutrition, J. K. R. Rodriguez, Ed., pp. 277-293, John Wiley \& Sons, Hoboken, NJ, USA, 2006. 
[141] Institute of Medicine, Committee on the Scientific Evaluation of Dietary Reference Intakes, Food and Nutrition Board, National Academy of Sciences, National Academy Press, Washington, DC, USA, 1998.

[142] R. J. Feuers, "The effects of dietary restriction on mitochondrial dysfunction in aging," Annals of the New York Academy of Sciences, vol. 854, pp. 192-201, 1998.

[143] S. Moghaddas, C. L. Hoppel, and E. J. Lesnefsky, "Aging defect at the QO site of complex III augments oxyradical production in rat heart interfibrillar mitochondria," Archives of Biochemistry and Biophysics, vol. 414, no. 1, pp. 59-66, 2003.

[144] J. Long, F. Gao, L. Tong, C. W. Cotman, B. N. Ames, and J. Liu, "Mitochondrial decay in the brains of old rats: ameliorating effect of alpha-lipoic acid and acetyl-Lcarnitine," Neurochemical Research, vol. 34, no. 4, pp. 755763, 2009. 

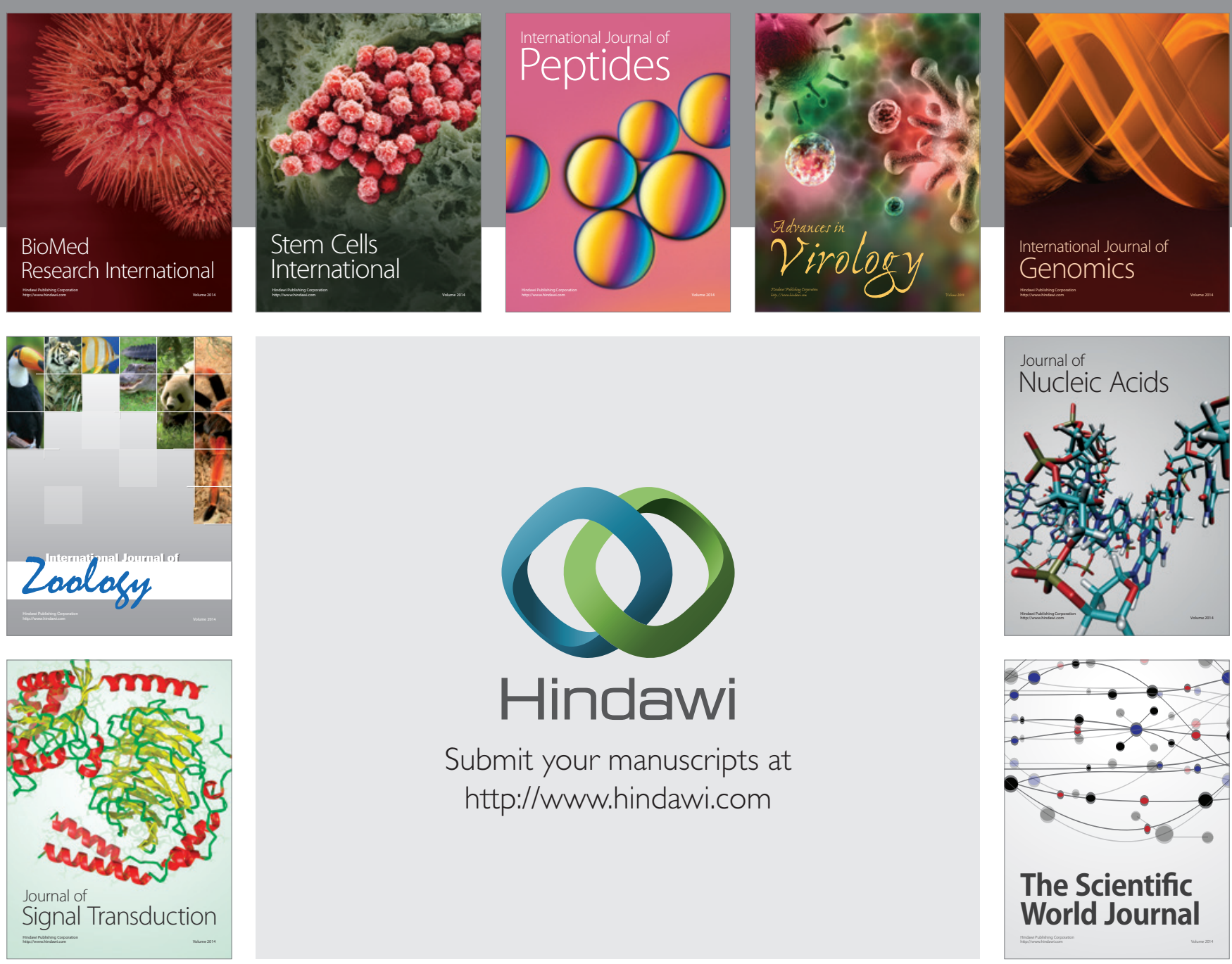

Submit your manuscripts at

http://www.hindawi.com
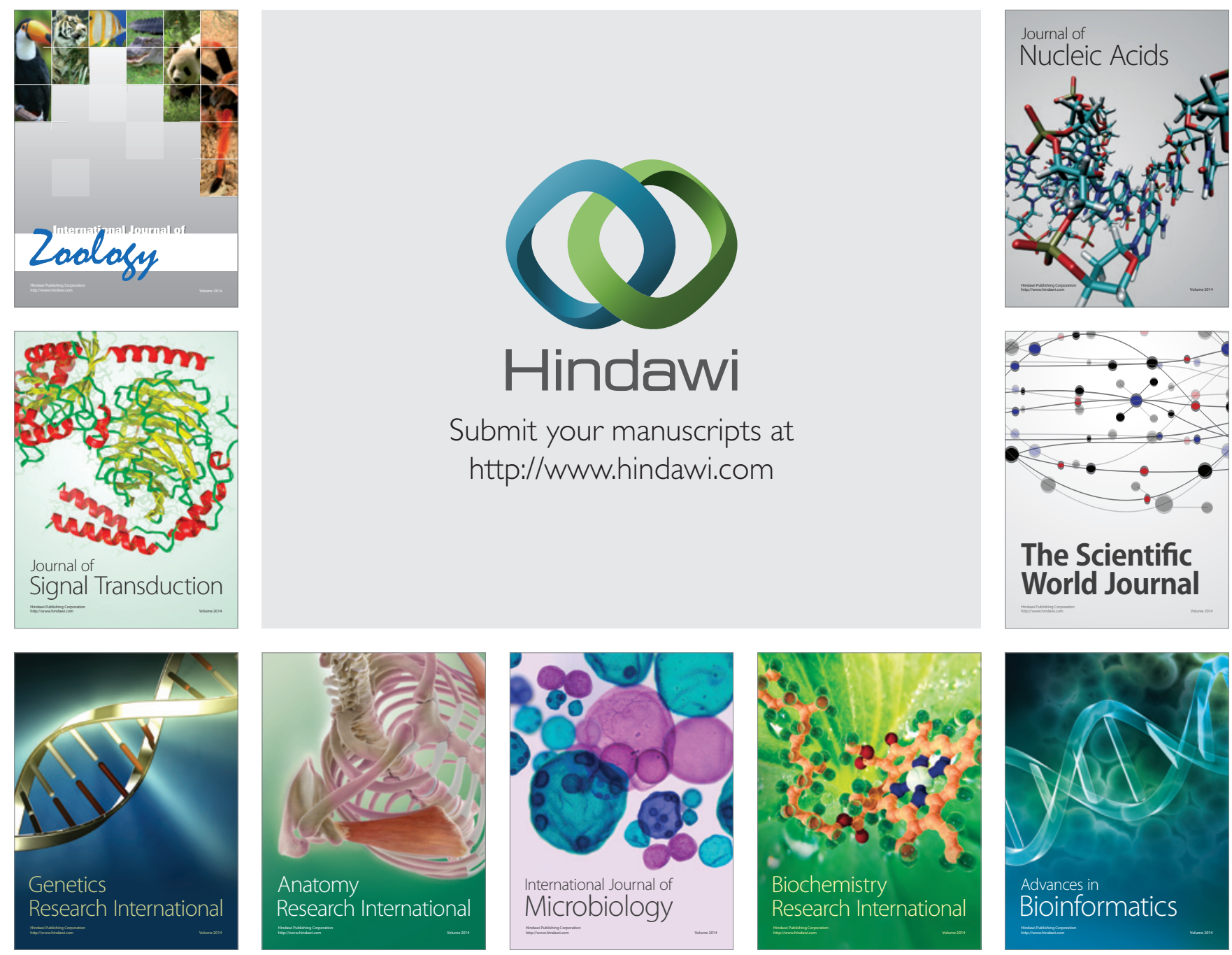

The Scientific World Journal
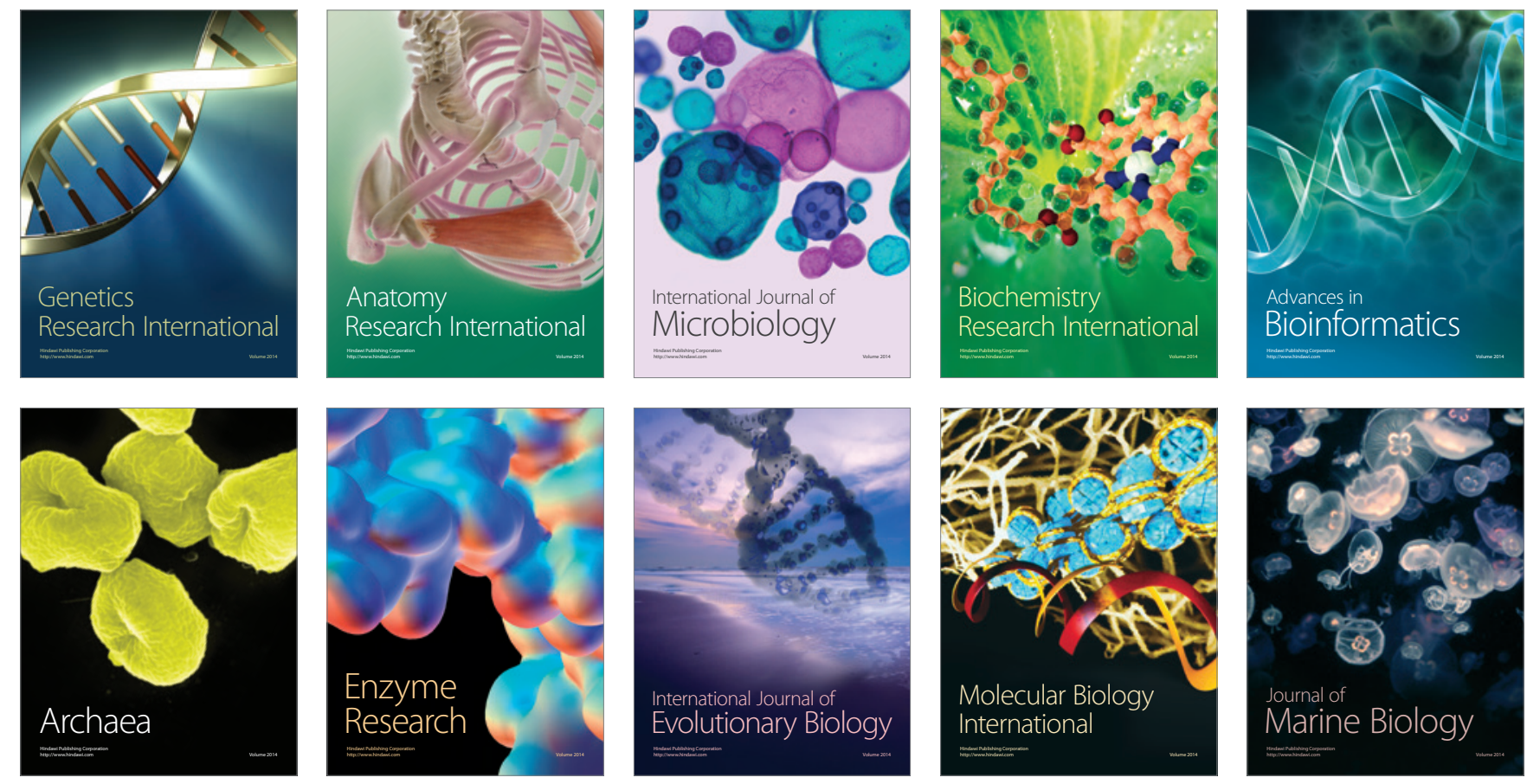